\title{
Increasing trend in Japan Sea Throughflow transport
}

\author{
Shinichiro Kida ${ }^{1}\left[\right.$ ] $\cdot$ Katsumi Takayama $^{1} \cdot$ Yoshi N. Sasaki $^{3} \cdot$ Hiromi Matsuura $^{2} \cdot$ Naoki Hirose $^{1}$ (i)
}

Received: 5 May 2020 / Revised: 18 August 2020 / Accepted: 19 August 2020 / Published online: 1 September 2020

(c) The Author(s) 2020

\begin{abstract}
A long-term increasing trend in the transport of the Japan Sea Throughflow is observed from sea-level differences across the Tsushima Strait. Tidal gauge observations show sea level at Hakata, Japan, increasing at a higher rate than that at Busan, Korea. Numerical modeling results suggest that this increasing trend is forced by a northward shift in the Kuroshio axis. As the Kuroshio axis moves northward, sea level along the southern coast of Japan increases. The signal then propagates anticyclonically along the coast as topographic Rossby waves and Kelvin waves, raising sea level and, thus, increasing transport through the Tsushima Strait.
\end{abstract}

Keywords Tsushima strait $\cdot$ Japan sea throughflow $\cdot$ Long-term trend $\cdot$ Sea-level rise $\cdot$ Kuroshio

\section{Introduction}

The sea surface temperature of the Japan Sea has risen by about $1.3-1.7^{\circ} \mathrm{C}$ over the last 100 years, roughly twice as much as the global ocean (Japan Meteorological Agency, State of the ocean climate 2020). Due to its location close to human activities, changes in the water mass properties of the Japan Sea are of vital importance to local climate and fisheries. One crucial element that controls the water mass properties of the Japan Sea, and, therefore, its circulation, is the Japan Sea Throughflow (JSTF; Kida et al. 2016). The Japan Sea is a semi-enclosed sea with connections to the surrounding seas limited to three major straits, the Tsushima, Tsugaru, and Soya Straits (Fig. 1). The JSTF is the flow through these three straits, which carries warm water from the south while the local atmosphere cools the oceanic water (Hirose et al. 1996). The dynamics that govern the long-term trends in JSTF transport provide the basis for understanding how the circulation and water mass properties of the Japan Sea will respond to climate change.

Shinichiro Kida

kida@riam.kyushu-u.ac.jp

1 Research Institute for Applied Mechanics, Kyushu University, Kasuga, Japan

2 Interdisciplinary Graduate School of Engineering Sciences, Kyushu University, Kasuga, Japan

3 Faculty of Science, Hokkaido University, Sapporo, Japan
Observations show that the Tsushima Strait serves as the entry point for the JSTF, whereas the Tsugaru and Soya Straits serve as exits. Because these three straits are only $50-150 \mathrm{~m}$ deep, the JSTF is concentrated near the surface $(\sim 200 \mathrm{~m})$. The Tsushima Strait is a well-observed strait, with an annual average transport of about $2.5 \mathrm{~Sv}$ (e.g., Takikawa et al. 2005; Fukudome et al. 2010), which brings warm subtropical surface water of the Kuroshio from the East China Sea to the Japan Sea. Outflow through the Tsugaru Strait to the Pacific is slightly greater than that through the Soya Strait to the Okhotsk Sea, where observations show the transport of about 1.5 Sv (Onishi and Ohtani 1997) and 1.0 Sv (Fukamachi et al. 2008), respectively.

Observing and understanding the mechanisms behind the long-term changes in JSTF transport is challenging, primarily due to its strong variability and lack of long-term monitoring. However, significant observational efforts during the 2000s based on acoustic Doppler current profiler (ADCP) measurements led to major improvements in our knowledge about the magnitude of the long-term average and climatological seasonal cycle of JSTF transport at the Tsushima Strait (Takikawa et al. 2005; Fukudome et al. 2010) and the Soya Strait (Ohshima et al. 2017). Winds over the North Pacific to the east of the Japan Sea have been found to control the long-term average of JSTF transport (e.g., Minato and Kimura 1980; Ohshima 1994; Tsujino et al. 2008), while the winds of the subpolar gyre and the Okhotsk Sea act as the dominant forcing agents in the seasonal cycle (e.g., Tsujino et al. 2008; Kida et al. 2016) 
Fig. 1 Three major straits of the Japan Sea Throughflow and the general direction of the flow. Color shows the climatological absolute sea surface height of the western North Pacific region and vectors show the geostrophic surface flow based on satellite altimetry from 1997 to 2012 (https://www.marine.coper nicus.eu). Inset shows a closeup image of the Tsushima Strait region, with blue dots indicating the locations of tidal gauge stations at Busan and Hakata

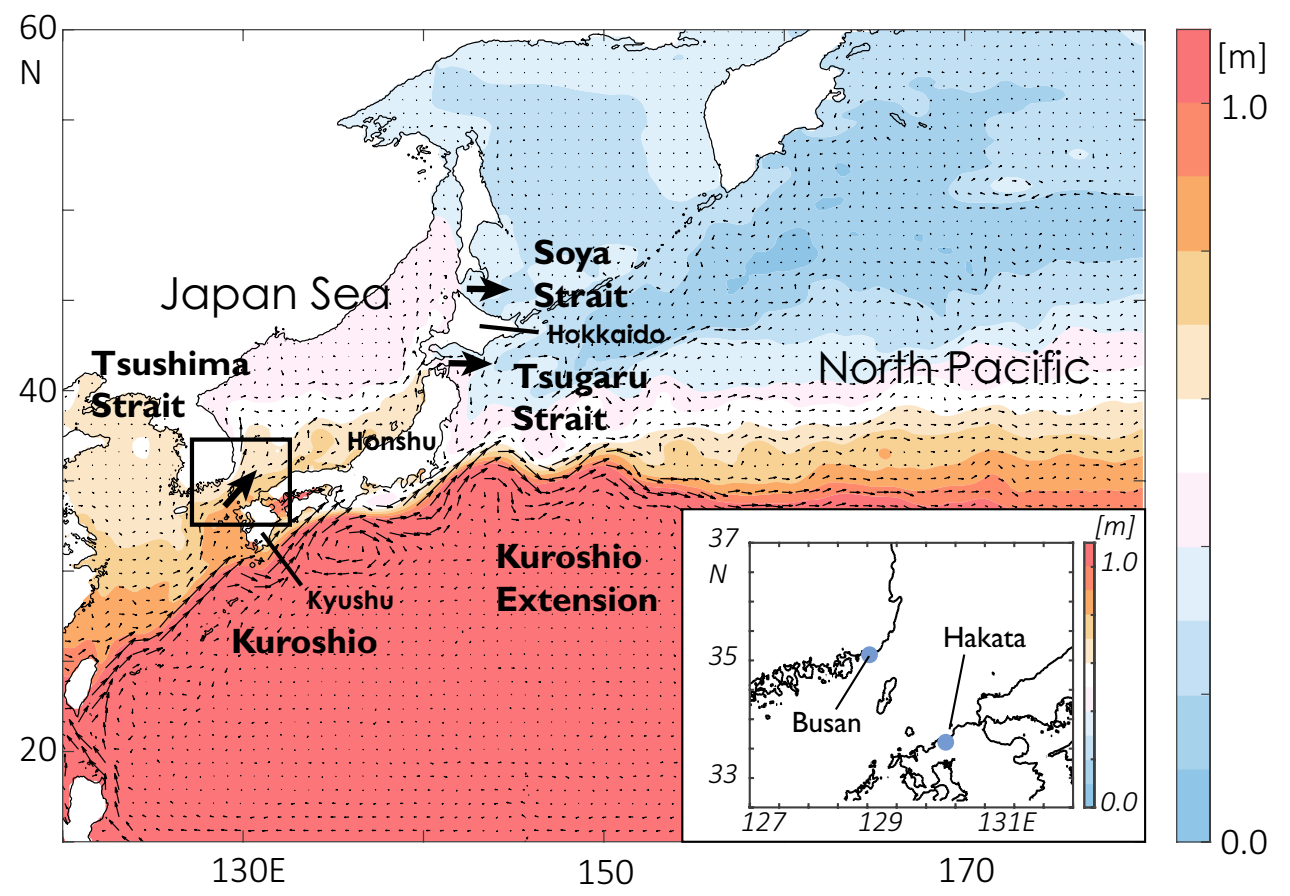

along with the Kuroshio south of Japan (Ma et al. 2012). The Kuroshio in the East China Sea varies seasonally and interannually (e.g. Andres et al. 2008; Hsin et al. 2013), and shows a weakening trend (Wang et al. 2016), but how much the variability affects JSTF transport is yet unclear. The direction of the topographic Rossby waves suggests perturbation along on the western coast of Kyushu, Japan may reach the Tsushima Strait while that along the continental slope of the East China Sea propagating southward, opposite to the direction of the Tsushima Strait. For variability at decadal and longer timescales, most research has focused on the interior of the Japan Sea. Variability in the upper oceanic water mass properties suggests an influence from atmospheric circulation, such as the Asian winter monsoon and Arctic Oscillation (Minobe et al. 2004; Na et al. 2012), and sea-level variability appears to correlate with the Pacific Decadal Oscillation (Gordon and Giulivi 2004).

In this study, we use sea-level data obtained at tidal gauges along the coast of Japan and Busan, Korea, to investigate long-term changes in JSTF transport across the Tsushima Strait. Changes in transport are estimated from sea-level differences across the strait, and the dynamics responsible for the long-term trend along the coast of Japan are investigated using a numerical model and sealevel data. The details of the sea-level data and the setup of the numerical model are described in Sect. 2. An increasing trend in JSTF transport and its possible mechanism are presented in Sect. 3. A summary and discussion are included in Sect. 4.

\section{Observations and the numerical model}

\subsection{Sea-level observations}

Annually averaged sea levels recorded at tidal gauges along the coast of Japan and in Busan, Korea are obtained for 1995-2018 through the Permanent Service for Mean Sea Level (Holgate et al. 2013; PSMSL 2020). To focus on the long-term changes, we take the 5-year running average of these data. The sea-level difference across the Tsushima Strait $(d \eta)$, from Hakata to Busan (Fig. 1), is used as a proxy for estimating the change in transport across the strait $(V)$. Assuming geostrophic balance, changes in the transport $(\Delta V)$ can be evaluated from the changes in sea-level difference $(\Delta(d \eta))$ :

$\Delta V \sim \frac{g}{f} \cdot \frac{\Delta(d \eta)}{d x} \cdot S$,

where $g$ is gravitational acceleration, $f$ is the Coriolis parameter $\left(\sim 8.3 \times 10^{-5} \mathrm{~s}^{-1}\right), d x$ is the distance across the strait $(\sim 200 \mathrm{~km})$, and $S$ is the cross-sectional area of the channel $\left(\sim 20 \mathrm{~km}^{2}\right)$. Note that Eq. 1 is based on geostrophy due to sea-level difference and not total transport. Baroclinic effect is known to be important in the western channel during summer (Isobe 1994; Lyu and Kim 2003), but is not examined in this study.

In addition to tidal gauges along the coast, satellite observations are used to examine the changes in the open ocean. SSALTO/DUACS Delayed-Time Level-4 sea surface height 
and geostrophic surface velocity from 1997 to 2012 (https:// www.marine.copernicus.eu) are used. To highlight the spatial differences, the estimated linear trend is offset by the regional average of $2.3 \mathrm{~mm}_{\text {year }}{ }^{-1}$.

\subsection{Numerical model setup}

RIAMOM, a numerical ocean model developed at Kyushu University (Hirose 2011), is used to investigate the mechanism underlying the increasing trend in JSTF transport observed at the Tsushima Strait. The model domain is $105^{\circ}-180^{\circ} \mathrm{E}$ and $15^{\circ}-63^{\circ} \mathrm{N}$, and the spatial resolution is $1 / 5^{\circ}$ and $1 / 4^{\circ}$ in the meridional and zonal directions, respectively. Lateral boundaries are based on the monthly climatology of the data assimilation product MOVE (Usui et al. 2006, 2015) from 1989 to 2012, with a sponge layer of about $500 \mathrm{~km}$ along the southern and eastern boundaries. To focus on the trends from 1989 to 2012, we forced the lateral boundaries by adding linear trends in temperature, salinity, and sea surface height gradient on top of the monthly climatological values. Linear trends are estimated based on differences in the 12-year averages between 1989-2000 and 2001-2012, and climatological values are estimated from the 24-year averages. The model is integrated from 1956 to 2014 using surface forcing derived from JRA55 (Kobayashi et al. 2015) for surface wind stress and heat flux. While surface forcing includes realistic variability over daily to decadal and longer time scales, lateral boundaries only consider the climatological seasonal cycle and long-term linear trend. All oceanic variability simulated within the model, aside from the seasonal cycle, is thus created internally or forced from the surface and does not include basin-scale decadal oscillations, regime shifts, or changes in steric height. This setup allows the role of the lateral boundary conditions of the model to be clarified. We will focus on the outputs from 1997 to 2012, after the model spun up and when estimates of JSTF transport based on ADCP measurements were available for validation (Utsumi 2018). The Kuroshio in the model followed the nonlarge meander path, in accordance with observations. Refer to Hirose (2011) for further numerical details of the model. Although the spatial resolution is moderate and barely sufficient to resolve the three straits of the Japan Sea, we consider the model applicable to this study because the magnitudes of JSTF transport at the three straits are well represented and because this model has been successfully used in previous studies to force nested high-resolution models (e.g., Hirose et al. 2013; Kim et al. 2019).

\section{Connection between the JSTF and Kuroshio}

\subsection{Trend of JSTF transport}

The changes in sea-level differences across the Tsushima Strait suggest a general increase in JSTF transport from 1995 to 2018 (Fig. 2a). The linear trend estimated for 1997-2012 is $1.0 \mathrm{~mm} \mathrm{year}^{-1}$; according to Eq. 1, this sea-level difference represents a transport change of about $0.11 \mathrm{~Sv}$ decade ${ }^{-1}$. The magnitude agrees well with the estimates based on ADCP measurements (Utsumi 2018), where an increasing trend of $0.13 \mathrm{~Sv}$ decade $^{-1}$ is observed for 1997-2012 (Fig. 2b). The increasing trend in JSTF transport estimated from tidal gauge observations appears to be a robust result. This increase in sea-level difference (or JSTF transport) is induced by the higher rate of the increase occurring at Hakata ( $3.6 \mathrm{~mm}_{\text {year }}{ }^{-1}$ ) compared to Busan (2.6 mm year ${ }^{-1}$ ) (Fig. 2a), indicating that sea-level changes along the coast of Japan are the primary driver of the long-term increasing trend in JSTF transport. The background increase in sea level does not play a role, as the difference in sea level affects transport, rather than its absolute value.

We next explored why the sea level at Hakata increased more rapidly than that at Busan utilizing the numerical model RIAMOM. The model results show the transport at the Tsushima Strait with an annual mean of $2.10 \mathrm{~Sv}$ and a linear trend of $0.11 \mathrm{~Sv}$ decade ${ }^{-1}$, similar to the estimates based on sea-level difference and ADCP measurements (Fig. 2a, b). Enhanced sea-level rise is also found on the Japanese side of the strait compared to the Korean side (Fig. 3a), analogous to observations. Changes in sea level and transport suggest that the model simulation captures the basic dynamics driving the long-term changes in JSTF transport.

The model results show that the positive linear trend in sea level at Hakata is part of a positive signal occurring along the southern and western coasts of Japan to the northern coast (Fig. 3a). Positive trends in sea level are found primarily to the west of the Kii Peninsula, with a maximum above $2 \mathrm{~mm}$ year $^{-1}$. Conversely, the region located to the east of the peninsula shows a decreasing trend of about $-1 \mathrm{~mm}$ year $^{-1}$ that continues counterclockwise to the Tsugaru Strait. At the Tsugaru Strait, a positive trend along the coast of the Honshu island of Japan suggests an enhancement of the cross-strait pressure gradient, representing increased transport. We find an increasing trend in transport through the Tsugaru Strait at $0.16 \mathrm{~Sv}$ decade $^{-1}$, which essentially balanced the increase at the Tsushima Strait (Fig. 2b). The trend found at the Soya Strait is smaller, at $0.03 \mathrm{~Sv}$ decade ${ }^{-1}$. 
[cm]

(a)

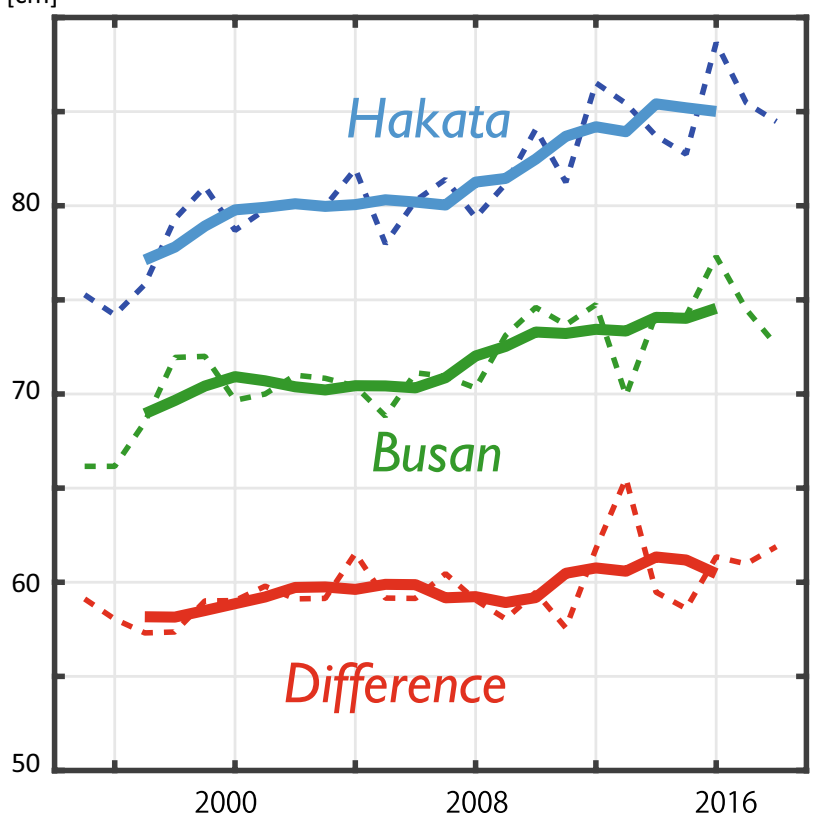

[Sv]

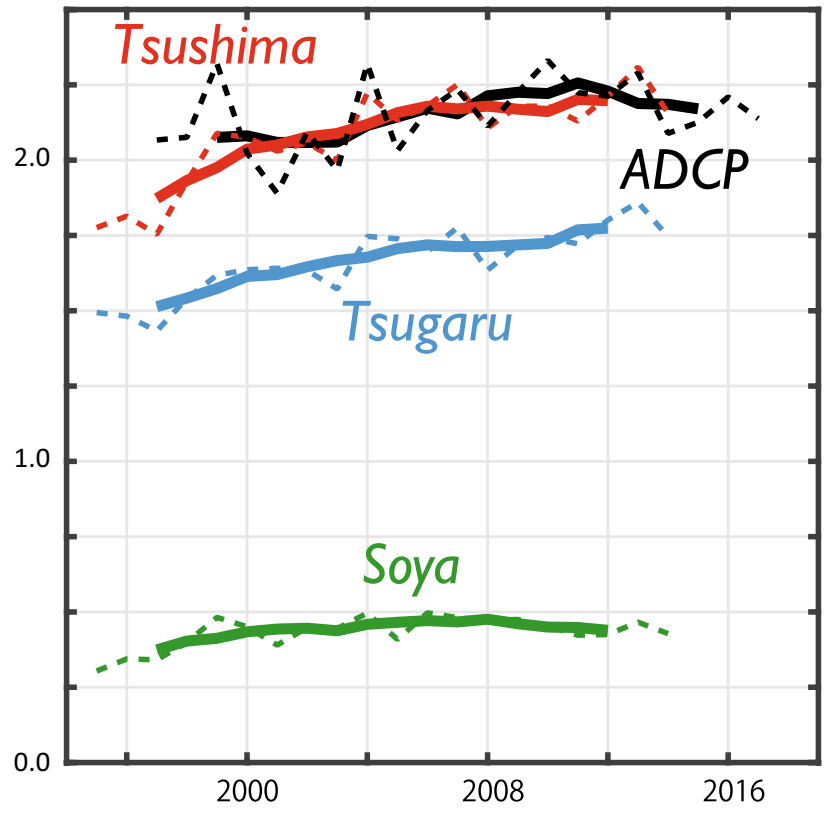

Fig. 2 a Annual average (dashed) and 5-year running average (solid) sea levels observed at tidal gauges at Hakata (blue; offset by $-100 \mathrm{~cm}$ ), Busan (green), and the difference (red; Hakata minus Busan offset by $-50 \mathrm{~cm})$. Sea levels are referenced to the local datum. b Annual average (dashed) and 5-year running average (solid) transports through the Tsushima Strait (red), Tsugaru Strait (blue), and Soya Strait (green) simulated in RIAMOM. Estimates based on acoustic Doppler current profiler observations along the Tsushima Strait are shown in black (Utsumi 2018) (color figure online)
The sea-level changes found from the southern coast to the western and northern coasts of Japan suggest a possible role of topographic Rossby waves and boundary-trapped Kelvin waves (Ma et al. 2010). These waves propagate anticyclonically along an island in the Northern Hemisphere; therefore, the positive signal beginning around the Kii Peninsula suggests that this region may be the origin of the sea level increase.

\subsection{Role of the northward shift of the Kuroshio and Kuroshio Extension (KE) axes}

When examining sea-level trends around Japan at a larger spatial scale, we find a strong positive trend just south of the Kii Peninsula (Fig. 3a). This signal is much stronger than that induced along the coast, indicating that it is the cause of the sea-level increase near the tip of the Kii Peninsula. This signal appears to be a component of the strong signal along the axis of the Kuroshio, which continues into the interior of the Pacific Ocean. Sea-level trends in the Pacific show strong signals, which are generally confined to the pathways of the Oyashio and the Kuroshio. The positive trend observed for the Oyashio is likely due to long-term changes in winds over the subpolar gyre (Qiu et al. 2015). By contrast, the zonally elongated dipole-like structures observed for the Kuroshio south of Japan and the KE are likely due to the northward shift in their axes. Because the Kuroshio is associated with an anticyclonic recirculation gyre and higher sea level on the southern (open ocean) side of its axis, a northward shift in the axis results in increased sea level on the northern (coastal) side of its axis and a decrease on the southern (open ocean) side, forming a dipole-like structure.

The model results show that a northward shift in the Kuroshio axis occurred from 1997 to 2012 (Fig. 3c). The Kuroshio axis is defined where the surface flow speed is strongest, which is a commonly used parameter to define the Kuroshio axis south of Japan (e.g., Ambe et al. 2004) and the KE jet (e.g., Taguchi et al. 2007). A northward shift in the Kuroshio would induce a strong increase in sea level at the southern tip of the Kii Peninsula, causing this region to force a sea-level increase along the coast of Japan. Around the southern tip of the Kii Peninsula, advection of the Kuroshio is strong and the mean Kuroshio path separates from the coast in the model. The climatological sea-level gradient across the Kuroshio in the area shows a maximum negative value of about $-40 \mathrm{~cm}(100 \mathrm{~km})^{-1}$ (Fig. 3b), which is somewhat weaker than observations but within the same order of magnitude (see Table 1 of Kida et al. 2015). The axis of the negative maximum sea-level gradient roughly corresponds to the area where the surface flow speed is strongest. A northward shift in the Kuroshio axis of about $0.5 \mathrm{~km}_{\text {year }}{ }^{-1}$ occurs in the model (Fig. 3c) and because the sea-level gradient near the Kii Peninsula is about $40 \mathrm{~cm}(100 \mathrm{~km})^{-1}$, this 
Fig. 3 a Linear trend in sea surface height and the surface flow field around Japan and b climatological sea surface height gradient (sum of zonal and meridional gradients) for RIAMOM from 1997 to 2012. Solid and dashed lines are the Kuroshio axes during 1997-2004 and 2005-2012, respectively. c Annually averaged location of the Kuroshio axis estimated as the meridional distance from the climatological axis (dashed). The solid line is the linear trend in 1997-2012 at $132.5-150^{\circ} \mathrm{E}$ (a)

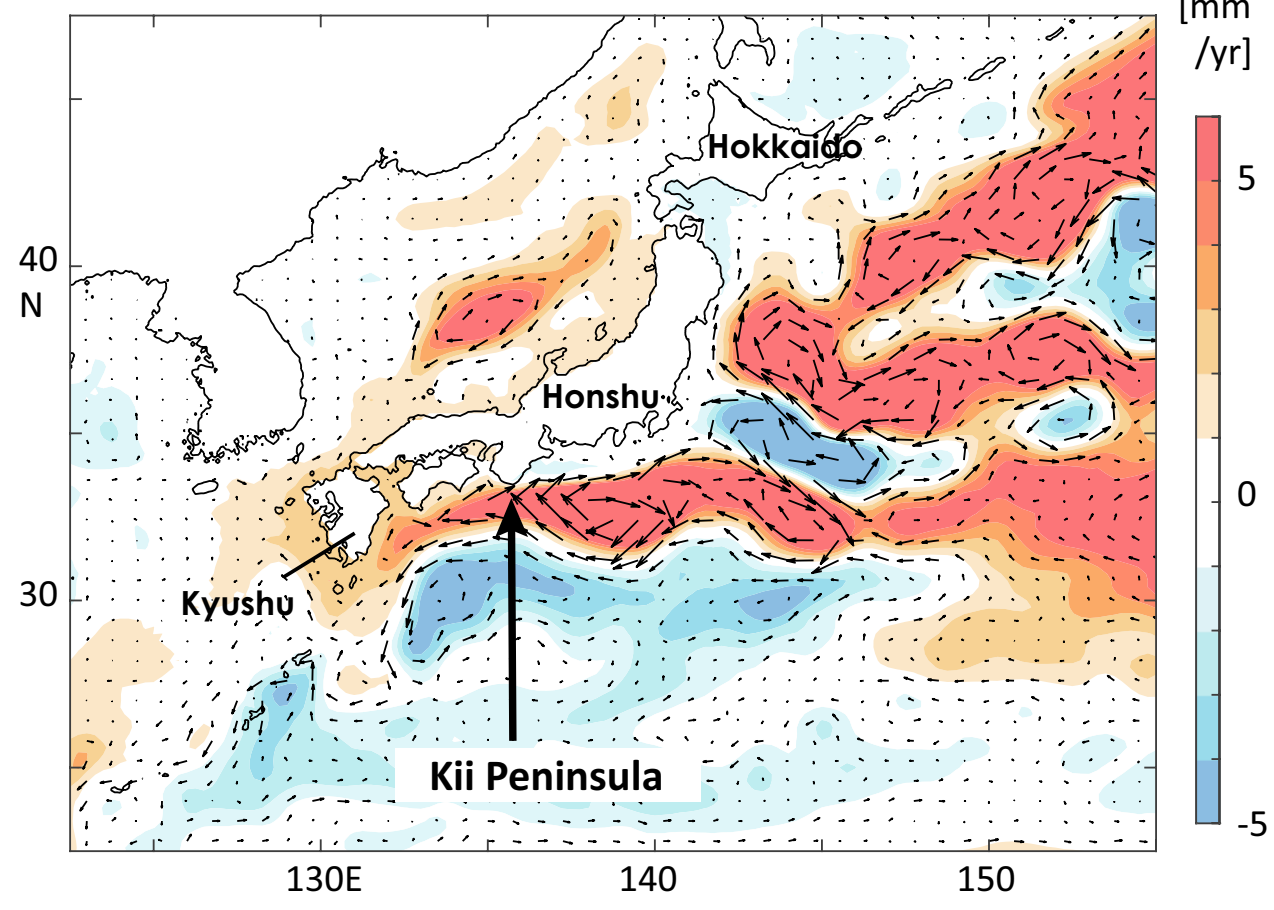

(b)

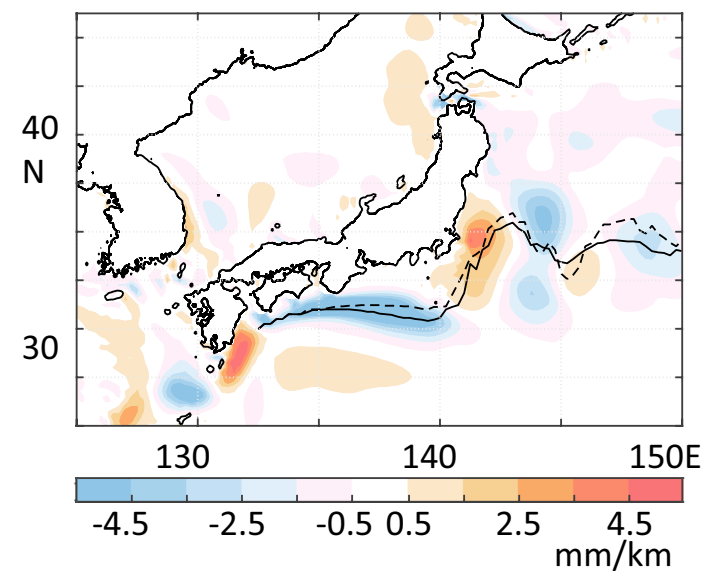

(c)

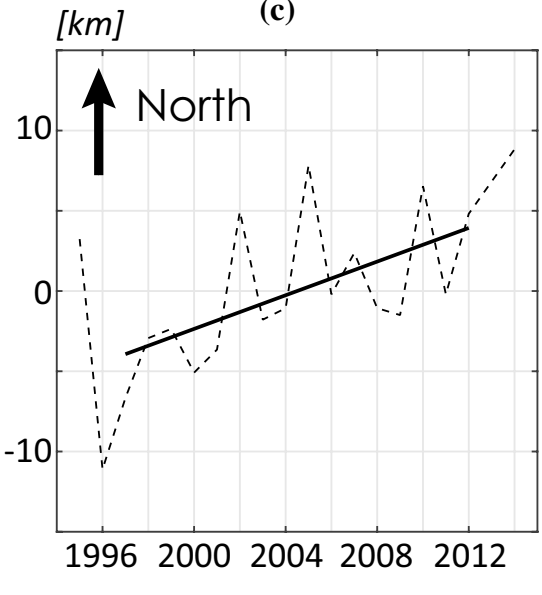

northward shift would induce a sea-level increase along the Kii Peninsula of about $2.0 \mathrm{~mm}_{\text {year }}{ }^{-1}$. This value aligns well with the magnitude of the sea-level increase in the model, confirming the role of the northward shift in the Kuroshio axis as a driver of the observed sea-level increase along the southern coast of Japan and Hakata (Fig. 4a), which in turns causes increased JSTF transport.

Next, we assess whether this role of the Kuroshio could also be found from satellite observations. Satellite altimetry shows a region with a strong positive trend in sea level just south of the Boso Peninsula, at about $35^{\circ} \mathrm{N}$ and $140^{\circ}$ E (Fig. 4a), which is the separation point of the Kuroshio. Sasaki et al. (2014) show that the positive sea-level trend induced in this region is connected to a northward shift in the Kuroshio axis and that its variability correlates well with sea-level variability observations at various tidal gauges along the coast of Japan. Our modeling results are qualitatively similar to these findings, as the southern tip of the Kii Peninsula is the separation point of the Kuroshio in the numerical model, whereas this occurs near the Boso Peninsula in the real ocean. The difference in the separation point is likely due to the spatial resolution of RIAMOM being inadequate to resolve the steep bathymetry of the Izu-Ogasawara Ridge south of the Boso Peninsula, which acts to limit the location of the Kuroshio passage towards the extension area (Ambe et al. 2004).

We further observe the sea-level changes along the coast of Japan correlating well with those at the tip of the Boso 
Fig. 4 a Linear trend in sea level based on satellite altimetry from 1997 to 2012 (https:// www.marine.copernicus.eu) offset by the regional average of $2.3 \mathrm{~mm}_{\text {year }}{ }^{-1}$. Red and blue circles indicate tidal gauges (https://www.psmsl.org) where sea levels are positively $(>0.5)$ and negatively $(<-0.5)$ correlated with that at Mera, Chiba, the tip of the Boso Peninsula, respectively, with a significance level of 95\%. Black circles are tidal gauges where the difference is non-significant or below 0.5 correlation. $\mathbf{b}$ Linear trend in sea level at tidal gauges shown in a based on the distance from Hakata. The left axis shows the magnitude of the trend. Distance is estimated along coastlines, with positive values in the cyclonic direction around the island of Japan. Black circles with pluses inside indicate where the correlations are non-significant or below 0.5. Black dots near the bottom show correlations with values on the right axis (a)

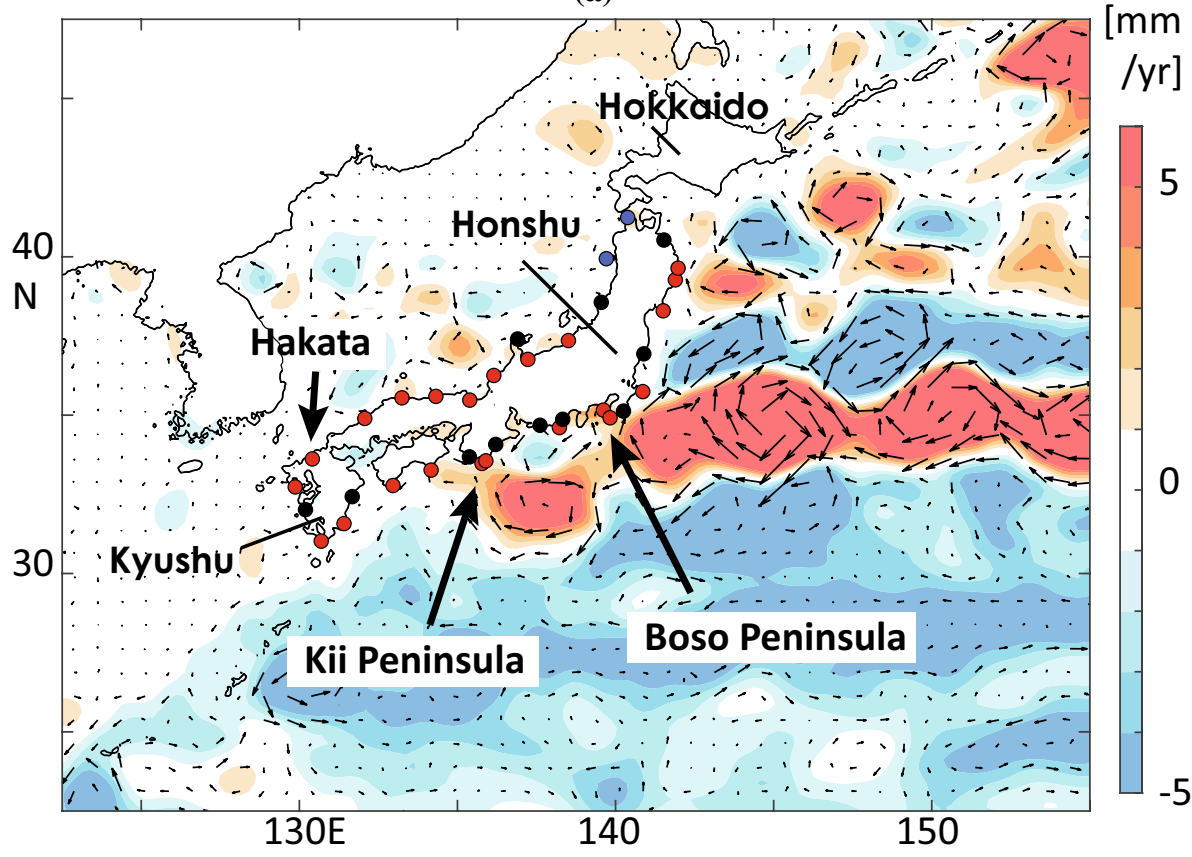

(b)

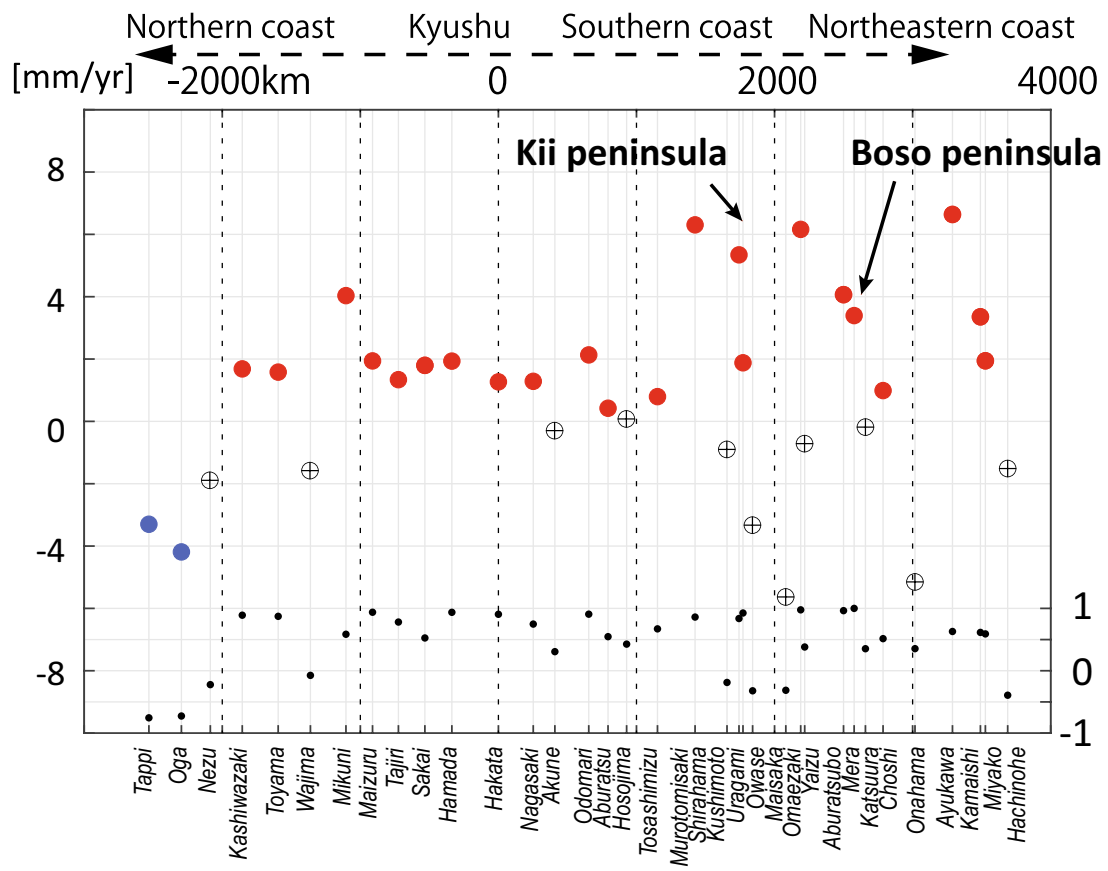

Peninsula (Mera, Chiba) (Fig. 4b). Note that the regionally averaged sea-level rise $\left(2.3 \mathrm{~mm}_{\mathrm{year}}{ }^{-1}\right)$ is excluded, allowing us to focus on differences within the region. Correlations are greater than 0.5 for most tidal gauges, but those in the northern region of Japan tend to be non-significant. Correlations found along the northeastern coast of the Honshu island may be due to the presence of an eddy-like feature near the coast, as captured in satellite altimetry (Fig. 4a), rather than a perturbation propagating along the coast. Non-significant correlations with sea-level variability at Owase and Maisaka, east of the Kii Peninsula, are likely due to regional complexity caused by the Kii Peninsula blocking the direct influence of the Kuroshio flow field. The simultaneous responses in sea level around Japan, from the south and west, to the northern coast is similar to the inter-annual signal propagating from the west to the northern coast reported by Senjyu et al. (1999), who suggested a role of the JSTF. However, in our analysis, the presence of this signal on the southern 
coast suggests that changes in the JSTF over a longer time scale are likely in response to sea-level changes, and not the reverse.

\section{Summary and discussion}

We found an increasing trend in JSTF transport based on sea-level data collected at tidal gauges across the Tsushima Strait. The increasing trend was about $0.11 \mathrm{~Sv}$ decade $^{-1}$ from 1997 to 2012 and appears to have continued until recently. We suspect that this increase in transport is driven by a rapid increase in sea level on the eastern side of the Tsushima Strait due to northward shifts in the Kuroshio and KE axes. Observations and numerical modeling experiments support the role of the Kuroshio and KE axes, showing that a northward shift in these axes brings the subtropical gyre, with higher sea level, toward the coast of Japan, which forces a rise in sea level along the coast. The perturbation signal in sea level propagates anticyclonically along the coast of Japan in the form of topographic Rossby waves and Kelvin waves, increases sea level along the eastern side of the Tsushima Strait, and enhances JSTF transport.

The variability of the Kuroshio and KE axes is complex, and previous studies have shown the importance of eddies and open-ocean winds. The Pacific Decadal Oscillation may be one cause of the gradual northward shift in the KE axis during 1997-2012 (Sasaki et al. 2013; Qiu et al. 2015). The northward shift in the KE axis can strengthen its southern recirculation gyre and induce sea-level increase along the southern coast of Japan (Fig. 3a). The KE and Kuroshio axes south of Japan are well correlated (Sugimoto and Hanawa 2012); therefore, a northward shift in the KE axis would likely to occur alongside a northward shift in the Kuroshio axis. The Kuroshio is known to follow three major paths south of Japan (Kawabe 1985), and the offshore and nearshore non-large meander paths were more commonly observed than the large meander path between 1997-2012 (Usui et al. 2013). The flow speed of the KE is greater when the Kuroshio follows the nearshore path compared to the offshore path (Qiu and Chen 2005), and the increasing trend in flow speed in the KE region (Sasaki et al. 2013) supports a transition from the offshore to the nearshore path during this period. Persistent large meander of the Kuroshio was observed about a year in 2004-2005 but not repeatedly during our analysis period, which may be one reason for the linear dynamical connection between the Kuroshio and JSTF identified in this study. The relationship between the location of the Kuroshio axis and its distance to the coast is likely to be more complex in the presence of a large meander, which requires further investigation.

We primarily explain the changes in JSTF transport based on changes in sea level and discuss the role of open-ocean processes in driving these long-term changes. The balance between throughflow and open-ocean processes can also be explained based on the momentum balance around an island using the island integral constraint (Yang 2007; Kida et al. 2016). Assuming a steady state, the island integral constraint implies that the frictional torque exerted by flow around an island must integrate to zero. The magnitude of the frictional torques exerted by the Kuroshio along the southern coast of Japan and by the JSTF along the straits must balance to satisfy this constraint (Fig. 5). If the frictional torque induced by the Kuroshio increases, so must that caused by the JSTF. Frictional torque due to the Kuroshio depends on its transport, western boundary layer width, and the distance it flows along the coast; therefore, any changes must occur in one of these factors. For the long-term trend in JSTF transport, the driving factor is the northward shift in the Kuroshio and $\mathrm{KE}$ axes, increasing the distance that the Kuroshio flows adjacent to the coast, not variability in Kuroshio transport (Fig. 5). A northward shift of the Kuroshio axis may narrow the distance between the coast and the Kuroshio axis. In contrast to the island rule (Godfrey 1989), this mechanism does not require a change in open-ocean wind stress. Because the frictional torque exerted by the JSTF is limited to areas along the straits, which have a constant length, the frictional torque of the JSTF is enhanced through an increase in its transport.

(a) Kuroshio axis is south

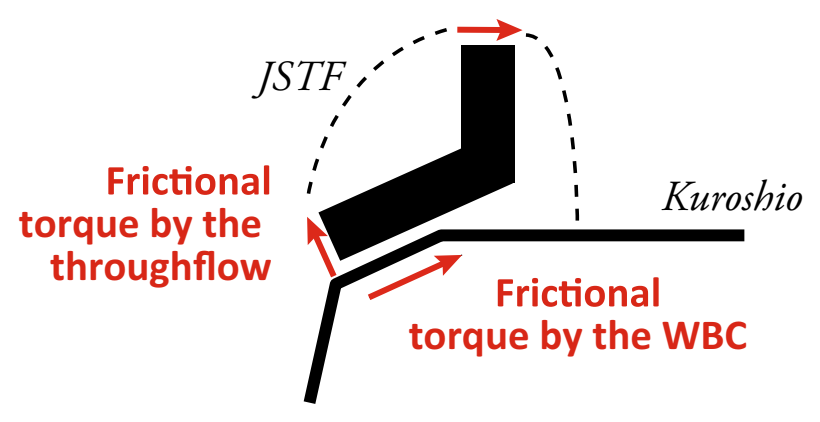

(b) Kuroshio axis moves north

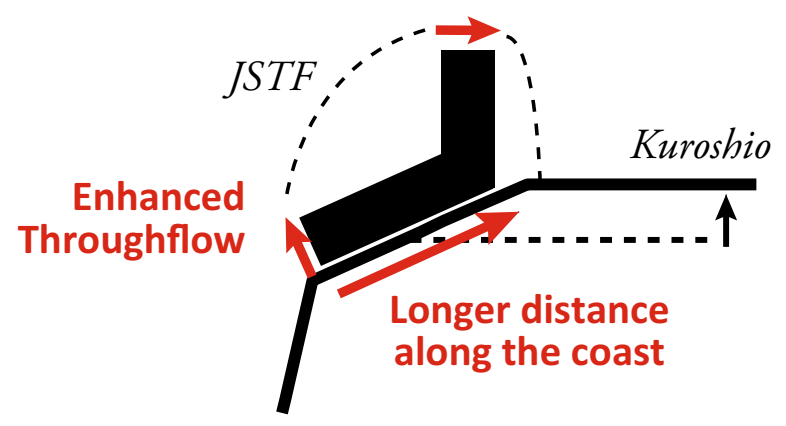

Fig. 5 Schematic of the frictional balance between the Kuroshio and Japan Sea Throughflow based on the location of the Kuroshio axis: a in the south and $\mathbf{b}$ when the axis moves northward 
In this study, we illustrate a dynamic connection between the Kuroshio and JSTF in their long-term trends using observations and numerical models. However, the mechanism behind variability in other time scales, such as decadal and inter-annual time scales, remains an open question. We also focus on the trends in the Tsushima Strait, rather than the Tsugaru and Soya Straits. In our numerical model, the increasing trend of JSTF transport at the Tsushima Strait is balanced by that through the Tsugaru Strait (Fig. 2b), but observations show a decreasing trend in sea level on the Japan Sea side of Tsugaru Strait (Tappi, Aomori) in 1997-2012. Whether transport through the Tsugaru Strait also shows an increasing trend remains unclear. However, sea level at the Soya Strait (Wakkanai, Hokkaido) shows an increasing trend. Sea levels at the Tsugaru and Soya Straits are likely to be directly influenced by changes in the Oyashio and the subpolar gyre, which may overwhelm the signal induced by the Kuroshio. Long-term monitoring of surface currents at the two straits with a high-frequency radar system is underway (Ebuchi et al. 2006; JAMSTECMORSETS 2020), which we hope will clarify the long-term trends described here.

Acknowledgements This work was supported by JSPS KAKENHI Grant Numbers JP16H02226, JP19H05698, and JP19K03960. The Ssalto/Duacs altimeter products were produced using the E.U. Copernicus Marine Service Information (https://www.marine.copernicus.eu). Annual-averaged sea levels were downloaded from Permanent Service for Mean Sea Level (https://www.psmsl.org). RIAMOM model results are freely available at DREAMS website (https://dreams-c.riam.kyush u-u.ac.jp) for academic purposes.

Open Access This article is licensed under a Creative Commons Attribution 4.0 International License, which permits use, sharing, adaptation, distribution and reproduction in any medium or format, as long as you give appropriate credit to the original author(s) and the source, provide a link to the Creative Commons licence, and indicate if changes were made. The images or other third party material in this article are included in the article's Creative Commons licence, unless indicated otherwise in a credit line to the material. If material is not included in the article's Creative Commons licence and your intended use is not permitted by statutory regulation or exceeds the permitted use, you will need to obtain permission directly from the copyright holder. To view a copy of this licence, visit http://creativecommons.org/licenses/by/4.0/.

\section{References}

Ambe D, Imawaki S, Uchida H, Ichikawa K (2004) Estimating the Kuroshio axis south of Japan using combination of satellite altimetry and drifting buoys. J Oceanogr 60(2):375-382

Andres M, Wimbush M, Park J-H, Chang K-I, Lim B-H, Watts DR, Ichikawa H, Teague WJ (2008) Observations of Kuroshio flow variations in the East China Sea. J Geophys Res 113:C05013. https://doi.org/10.1029/2007JC004200

Ebuchi N, Fukamachi Y, Ohshima KI, Shirasawa K, Ishikawa M, Takatsuka T, Wakatsuchi M (2006) Observation of the Soya Warm Current using HF ocean radar. J Oceanogr 62(1):47-61
Fukamachi Y, Tanaka I, Ohshima KI, Ebuchi N, Mizuta G, Yoshida H, Wakatsuchi M (2008) Volume transport of the Soya Warm Current revealed by bottom-mounted ADCP and ocean-radar measurement. J Oceanogr 64(3):385-392

Fukudome KI, Yoon JH, Ostrovskii A, Takikawa T, Han IS (2010) Seasonal volume transport variation in the Tsushima Warm Current through the Tsushima Straits from 10 years of ADCP observations. J Oceanogr 66(4):539-551

Godfrey JS (1989) A Sverdrup model of the depth-integrated flow for the world ocean allowing for island circulations. Geophys Astrophys Fluid Dyn 45(1-2):89-112

Gordon AL, Giulivi CF (2004) Pacific decadal oscillation and sea level in the Japan/East Sea. Deep Sea Res Part I 51(5):653-663

Hirose N (2011) Inverse estimation of empirical parameters used in a regional ocean circulation model. J Oceanogr 67(3):323-336

Hirose N, Kim CH, Yoon JH (1996) Heat budget in the Japan Sea. J Oceanogr 52(5):553-574

Hirose N, Takayama K, Moon JH (2013) Regional data assimilation system extended to the East Asian marginal seas. Umi Sora (Sea Sky) 89(2):1-9

Holgate SJ, Matthews A, Woodworth PL, Rickards LJ, Tamisiea ME, Bradshaw E, Pugh J (2013) New data systems and products at the permanent service for mean sea level. J Coast Res 29(3):493-504

Hsin YC, Qiu B, Chiang TL, Wu CR (2013) Seasonal to interannual variations in the intensity and central position of the surface Kuroshio east of Taiwan. J Geophys Res Oceans 118(9):4305-4316

Isobe A (1994) Seasonal variability of the barotropic and baroclinic motion in the Tsushima-Korea Strait. J Oceanogr 50(2):223-238

Japan Agency for Marine-Earth Science and Technology MORSETS website (2020). MIO ocean radar data site for Eastern Tsugaru Strait. https://www.godac.jamstec.go.jp/morsets/e/top/. Accessed 18 Apr 2020

Japan Meteorological Agency (2020). State of the ocean climate, https ://www.data.jma.go.jp/gmd/kaiyou/english/long_term_sst_japan /sea_surface_temperature_around_japan.html. Accessed 14 Apr 2020

Kawabe M (1985) Sea level variations at the Izu Islands and typical stable paths of the Kuroshio. J Oceanogr Soc Jpn 41(5):307-326

Kida S, Mitsudera H, Aoki S, Guo X, Ito SI, Kobashi F, Nakamura H (2015) Oceanic fronts and jets around Japan: a review. J Oceanogr 71(5):469-497

Kida S, Qiu B, Yang J, Lin X (2016) The annual cycle of the Japan Sea Throughflow. J Phys Oceanogr 46(1):23-39

Kim H, Takayama K, Hirose N, Onitsuka G, Yoshida T, Yanagi T (2019) Biological modulation in the seasonal variation of dissolved oxygen concentration in the upper Japan Sea. J Oceanogr 75(3):257-271

Kobayashi S, Ota Y, Harada Y, Ebita A, Moriya M, Onoda H, Miyaoka K (2015) The JRA-55 reanalysis: general specifications and basic characteristics. J Meteorol Soc Jpn Ser II 93(1):5-48

Lyu SJ, Kim K (2003) Absolute transport from the sea level difference across the Korea Strait. Geophys Res Lett 30(6):1285. https://doi. org/10.1029/2002GL016233

Ma C, Yang J, Wu D, Lin X (2010) The Kuroshio Extension: a leading mechanism for the seasonal sea-level variability along the west coast of Japan. Ocean Dyn 60(3):667-672

Ma C, Wu D, Lin X, Yang J, Ju X (2012) On the mechanism of seasonal variation of the Tsushima Warm Current. Cont Shelf Res $48: 1-7$

Minato S, Kimura R (1980) Volume transport of the western boundary current penetrating into a marginal sea. J Oceanogr Soc Jpn 36(4):185-195

Minobe S, Sako A, Nakamura M (2004) Interannual to interdecadal variability in the Japan Sea based on a new gridded upper water temperature dataset. J Phys Oceanogr 34(11):2382-2397 
Na H, Kim KY, Chang KI, Park JJ, Kim K, Minobe S (2012) Decadal variability of the upper ocean heat content in the East/Japan Sea and its possible relationship to northwestern Pacific variability. J Geophys Res Oceans 117:C02017. https://doi.org/10.1029/2011J C007369

Ohshima KI (1994) The flow system in the Japan Sea caused by a sea level difference through shallow straits. J Geophys Res Oceans 99(C5):9925-9940

Ohshima KI, Simizu D, Ebuchi N, Morishima S, Kashiwase H (2017) Volume, heat, and salt transports through the Soya Strait and their seasonal and interannual variations. J Phys Oceanogr 47(5):999-1019

Onishi M, Ohtani K (1997) Volume transport of the Tsushima Warm Current, west of Tsugaru Strait bifurcation area. J Oceanogr 53(1):27-34

Permanent Service for Mean Sea Level (PSMSL) (2020) Tide gauge data. Retrieved 15 Apr 2020 from https://www.psmsl.org/data/ obtaining/

Qiu B, Chen S (2005) Variability of the Kuroshio Extension jet, recirculation gyre, and mesoscale eddies on decadal time scales. J Phys Oceanogr 35(11):2090-2103

Qiu B, Chen S, Wu L, Kida S (2015) Wind-versus eddy-forced regional sea level trends and variability in the North Pacific Ocean. J Clim 28(4):1561-1577

Sasaki YN, Minobe S, Schneider N (2013) Decadal response of the Kuroshio Extension jet to Rossby waves: observation and thin-jet theory. J Phys Oceanogr 43(2):442-456

Sasaki YN, Minobe S, Miura Y (2014) Decadal sea-level variability along the coast of Japan in response to ocean circulation changes. J Geophys Res Oceans 119(1):266-275

Senjyu T, Matsuyama M, Matsubara N (1999) Interannual and decadal sea-level variations along the Japanese coast. J Oceanogr 55(5):619-633
Sugimoto S, Hanawa K (2012) Relationship between the path of the Kuroshio in the south of Japan and the path of the Kuroshio Extension in the east. J Oceanogr 68(1):219-225

Taguchi B, Xie SP, Schneider N, Nonaka M, Sasaki H, Sasai Y (2007) Decadal variability of the Kuroshio Extension: observations and an eddy-resolving model hindcast. J Clim 20(11):2357-2377

Takikawa T, Yoon JH, Cho KD (2005) The Tsushima warm current through Tsushima Straits estimated from ferryboat ADCP data. J Phys Oceanogr 35(6): 1154-1168

Tsujino H, Nakano H, Motoi T (2008) Mechanism of currents through the straits of the Japan Sea: mean state and seasonal variation. J Oceanogr 64(1):141-161

Usui N, Ishizaki S, Fujii Y, Tsujino H, Yasuda T, Kamachi M (2006) Meteorological Research Institute multivariate ocean variational estimation (MOVE) system: Some early results. Adv Space Res 37(4):806-822

Usui N, Tsujino H, Nakano H, Matsumoto S (2013) Long-term variability of the Kuroshio path south of Japan. J Oceanogr 69(6):647-670

Usui N, Fujii Y, Sakamoto K, Kamachi M (2015) Development of a four-dimensional variational assimilation system for coastal data assimilation around Japan. Mon Weather Rev 143(10):3874-3892

Utsumi Y (2018) Reanalysis of the flow field across the Tsushima Strait estimated from ferry boat ADCP data. Master's thesis, Interdisciplinary Graduate School of Engineering Sciences, Kyushu University

Wang YL, Wu CR, Chao SY (2016) Warming and weakening trends of the Kuroshio during 1993-2013. Geophys Res Lett 43(17):9200-9207

Yang J (2007) An oceanic current against the wind: how does Taiwan Island steer warm water into the East China Sea? J Phys Oceanogr 37(10):2563-2569 